\title{
Human privacy respect from viewpoint of hospitalized patients
}

\author{
Fatemeh Valizadeh, Seyyedeh Fatemeh Ghasemi
}

Nursing and Midwifery Faculty, Lorestan University of Medical Sciences, Lorestan, Khorramabad, Iran

This article is distributed under the terms of the Creative Commons Attribution Noncommercial License (CC BY-NC 4.0) which permits any noncommercial use, distribution, and reproduction in any medium, provided the original author(s) and source are credited.

\begin{abstract}
Patient-oriented care is for nurses a holistic science, of which the patient's privacy respect is an essential part. The aim of this study was to determine the hospitalized patients' viewpoints concerning their privacy respect. This descriptive, analytic and cross-sectional research administered to 370 patients that were selected through a random-stratified sampling in an educational hospital in the Khorramabad in Iran in 2013-2014. Data were collected by a questionnaire about respect of the patient's privacy by hospital staff, including physicalcorporeal, psycho-mental, and informational domains. Data were gathered through constructed interviews and analyzed with Independent t-test, One-way ANOVA and Pearson correlation statistical tests. The privacy of patients and its physical-corporeal and informational domains were sometimes observed, while the psycho-mental domain was often respected. The privacy respect was significantly lower for male patients $(\mathrm{p}=0.000)$ in the emergency department, and with patients who spoke with a local accent $(\mathrm{p}=0.016)$. It seems necessary to train the health care providers to have more respect in terms of patient physical-corporeal and informational privacy, to observe male patient privacy and to use all interpersonal communication skills when dealing with non-Persian language patients. Furthermore, it seems necessary to revise the structure and design of emergency departments in order to protect the privacy of the patients.
\end{abstract}

Key Words: Human privacy, patient rights, patient-oriented care

Eur J Transl Myol 30 (1): xx1-xx8, 2020

The protection of privacy has been a basic and important necessity for human beings and nursing. ${ }^{1}$ Because it may support mental, social, and natural performance of health care-takers, it is significantly taken into account. ${ }^{2}$ Preserving privacy is a necessary factor to create a patient-oriented, individualized care that responds to ethical rules. ${ }^{3}$ World Health Organization inserted it in the ethical principles of medicine and in the declaration of the promotion of patients rights in $1994 .^{4}$ On the Bill of patients rights in Iran, it is also emphasized that delivering health services must be based on the observance of patient privacy, including patient confidentiality. ${ }^{5}$ When we mention privacy, we are talking about a variety of domains, physical, informational, mental, and social. ${ }^{6}$ If privacy is respected, persons will feel free to answer questions. ${ }^{7}$ The personal privacy observance of persons builds an effective relationship with treatment staff and creates a feeling of independence, importance, calm, welfare, security and identity that meet these needs and will be an indispensable part of persons recovery. ${ }^{7-10}$ Indeed, privacy violation consequences are many: patient may famish his clinical history; avoid physical examination; feeling fear, anxiety, stress, irritating rough and aggressive behaviors, he may create tension, lacking of asking help, he may avoid of being cared, interrupting the process of treatment, decreasing collaboration, and he may change the sleeping hours. ${ }^{10-14}$ Privacy violations also can affect the whole system of health care. ${ }^{15}$ There is a significant relationship between the patients satisfaction and their privacy respect in Dehghan Nayeri and Aghajani (2010) study. ${ }^{16}$ Since patient satisfaction is taken into account as one of the quality indices in care treatments, observing patient privacy will actually improve the quality of care. ${ }^{16}$ Health care providers should be aware of their patient's religion, culture and believes, and know-how to enter the individuals personal space. ${ }^{17}$ In order to deliver appropriate and culturerelated care, personal privacy must be significantly taken into account. ${ }^{18}$ This study was performed to determine the rate of human privacy observance from the hospitalized patient viewpoint. It helps us to reveal the domains of privacy that is less taken into account by the entire medical staff. 
Table1. The observance rate of human privacy and its domains based on the hospitalized patients' viewpoints

\begin{tabular}{|l|l|l|l|l|l|l|}
\hline Domain & Nevervance Rate & Hardly ever & Sometimes & Often & Always & Mean \pm SD \\
\hline Corporeal- physical & - & $\mathbf{2 4}(\mathbf{6 . 5})$ & $\mathbf{1 7 1}(\mathbf{4 6 . 2})$ & $\mathbf{1 3 6}(\mathbf{3 6 . 8})$ & $\mathbf{3 9}(\mathbf{1 0 . 5})$ & $\mathbf{5 8 . 9 2} \pm \mathbf{1 4 . 7 0}$ \\
\hline Psycho-mental & $\mathbf{1}(\mathbf{0 . 2})$ & $\mathbf{3 1}(\mathbf{8 . 4})$ & $\mathbf{1 3 8}(\mathbf{3 7 . 3})$ & $\mathbf{1 4 8 ( 4 0 )}$ & $\mathbf{5 2}(\mathbf{1 4 . 1})$ & $\mathbf{5 0 . 6} \pm \mathbf{1 2 . 8 1}$ \\
\hline Informational & $\mathbf{1 ( 0 . 2 )}$ & $\mathbf{1 9}(\mathbf{5 . 1})$ & $\mathbf{2 0 3}(\mathbf{5 4 . 9})$ & $\mathbf{1 2 9}(\mathbf{3 4 . 9})$ & $\mathbf{1 8}(\mathbf{4 . 9})$ & $\mathbf{2 9 . 5 7} \pm \mathbf{6 . 3 6}$ \\
\hline Total privacy & - & $\mathbf{1 1}(\mathbf{3 . 0})$ & $\mathbf{1 7 6}(\mathbf{4 7 . 6})$ & $\mathbf{1 4 9}(\mathbf{4 0 . 2})$ & $\mathbf{3 4}(\mathbf{9 . 2})$ & $\mathbf{1 3 9 . 1 3} \pm \mathbf{2 9 . 6 5}$ \\
\hline
\end{tabular}

\section{Materials and Methods}

In this descriptive, cross-sectional and analytical study, the subjects included 370 hospitalized patients in different wards of an educational hospital in Khorramabad during the year 2013-2014. The number of subjects was calculated based on the formula of proportion estimation for the population, $\alpha=0.05$, and Ghasemi's et al. study. ${ }^{19}$ The sampling method was a combination of simple and stratified random methods. Different wards were considered as stratifications. The number of patients in each ward in relation to the hospitalization proportion of patients was selected by using the bed numbers and the table of random numbers. The inclusion criteria were being at least 15-year old, being conscious, lack of a level of pain that prevented the patient from answering the questions, and being hospitalized at least 24 hours. The exclusion criterion was the patient general status getting worse during the interview. The data collecting instrument consisted of three sections. In the first section, individual specifications were asked which included: age, gender, occupation, education, marital status, diagnosis, accent, ward, duration and type of hospitalization, number of beds in rooms, and the history of reading the Bill of patients rights. In the second section, the rate of observance of patients privacy by the hospital staff was assessed by asking 45 questions including physicalcorporeal (19 questions), psycho-mental (16 questions), and informational (10 questions) domains. The responses were based on the five-level item of Likert Scale. That is; never (1 point), hardly ever (2 points), sometimes (3 points), often (4 points), and always (5 points) were scored. For some questions, since information privacy was not in line with privacy observance, scoring was calculated inversely. Regarding total privacy, the calculated score for each patient was in the range of 45225 . The rate of privacy observance was classified into 5 sections based on the total score. In the third section, few short-answer questions were asked to the patients containing "How do you feel toward violating privacy observance?" "Suppose you want to score staff based on observing privacy, what mark you'll give out of 10 to each job category (physicians, nurses, service delivery, security guards, patient carriers, students, and staff of laboratory and radiology wards)? And "when your privacy is observed less?". The tool validity was determined based on qualitative content validity and consulting with five faculty members of the nursing department of Nursing-Midwifery College in Khorramabad. Its reliability was calculated by a pilot study on 50 patients and obtained the coefficient of internal correlation of Cronbach's Alpha, which $\alpha$ for the whole questionnaire, corporeal-physical, psycho-mental and informational sub-scales were $0.83,0.76,0.89$ and 0.79 respectively. Data collecting method was constructed interview. All interviews were conducted by two interviewers, with the same gender of the patients. They were not employed in that hospital and trained how to express questions to be understandable for patients. Interviews were done in the evening shift and each interview lasted within 30 to 40 minutes. Ethical considerations, including receiving permission from the hospital, introducing the purpose of the research to the patients, emphasizing on voluntary participation, remaining answers confidential, were highly regarded. Because the scores on privacy observance had a normal distribution, parametric statistical tests were employed such as frequency, percentage, mean, independent t-test, one-way variance analysis, and Pearson correlation test.

\section{Results}

The age-range of the subjects was from 15 to 85 , the mean and the standard deviation (SD) were 42.10 \pm 1.81 . The rate of the total privacy observance was between 46225 , the patient's privacy was observed only sometimes (Table1).

In corporeal-physical privacy domain, the highest mean of repentance was related to avoid touching the patient's body when not necessarily $(3.65 \pm 1.35)$, avoiding, for instance, to sit on patient bed $(3.62 \pm 1.39)$, independently from the different staff gender $(3.48 \pm 1.34)$, and covering parts of their bodies while being examined or cared if not necessary $(3.47 \pm 1.28)$. The lowest mean of corporealphysical privacy observance were: staff don't knock at the door when they enter in the patient room $(2.35 \pm 1.32)$, the patients are not adequately introduced to people in the ward when admitted in the hospital (2.48 \pm 1.51$)$, permission was not taken when other people, as university students will be present during diagnostic and therapeutic procedures $(2.61 \pm 1.27)$, not paying attention to patient personal space $(2.91 \pm 1.17)$, not covering patient after finishing care or shuting the door when medical staff are leaving the room $(2.92 \pm 1.32)$. 
Table 2. Hospitalized patients viewpoints on observance rate of human privacy based on individual specifications

\begin{tabular}{|c|c|c|c|c|c|}
\hline \multicolumn{2}{|l|}{ Demographic Specifications } & $\mathrm{N}(\%)$ & $\mathbf{M} \pm \mathbf{S D}$ & Test & $\mathbf{P}$ \\
\hline \multirow[t]{4}{*}{ Age(year) } & $<20$ & $36(7.9)$ & $136.97 \pm 20.14$ & \multirow{4}{*}{$* 1.21$} & \multirow{4}{*}{0.31} \\
\hline & $20-35$ & $121(32.7)$ & $141.40 \pm 30.15$ & & \\
\hline & $36-60$ & $39(37.6)$ & $140.40 \pm 30.38$ & & \\
\hline & $>60$ & $74(20)$ & $\mathbf{1 3 3 . 7 3} \pm \mathbf{3 0 . 7 6}$ & & \\
\hline \multirow{2}{*}{ Gender } & female & $168(45.4)$ & $155.23 \pm 30$ & \multirow{2}{*}{$* * 9.12$} & \multirow{2}{*}{0.000} \\
\hline & male & $202(54.6)$ & $127.29 \pm 23.48$ & & \\
\hline \multirow[t]{4}{*}{ Education } & illiterate & $92(24.6)$ & $141.87 \pm 33.60$ & \multirow{4}{*}{$* 0.75$} & \multirow{4}{*}{0.22} \\
\hline & $\begin{array}{l}\text { Unaccomplished } \\
\text { diploma }\end{array}$ & $120(32.5)$ & 138.18 $\pm \mathbf{2 7 . 0 7}$ & & \\
\hline & diploma & $72(19.6)$ & 139.76 \pm 32.14 & & \\
\hline & university & $86(23.3)$ & $135.30 \pm 26.04$ & & \\
\hline \multirow{3}{*}{$\begin{array}{l}\text { Marital } \\
\text { status }\end{array}$} & single & $109(29.5)$ & $136.85 \pm 26.32$ & \multirow{3}{*}{$* 0.5$} & \multirow{3}{*}{0.61} \\
\hline & married & $238(64.3)$ & $139.76 \pm 31.29$ & & \\
\hline & widow/ widower & $23(6.2)$ & $142.26 \pm 26.26$ & & \\
\hline \multirow[t]{3}{*}{ Accent } & Lori & $225(60)$ & $139.92 \pm 31.10$ & \multirow{3}{*}{$* 4.21$} & \multirow{3}{*}{0.016} \\
\hline & Laki & $123(32.8)$ & $134.82 \pm 28.53$ & & \\
\hline & Persian & $27(7.2)$ & $153.95 \pm 25.26$ & & \\
\hline \multirow[t]{2}{*}{ Hospitalization history } & Yes & $170(46.7)$ & $\mathbf{1 3 7 . 8 9} \pm \mathbf{3 0 . 3 8}$ & \multirow{2}{*}{$* * 0.70$} & \multirow{2}{*}{0.48} \\
\hline & No & $200(53.3)$ & $140 \pm 38.93$ & & \\
\hline \multirow{3}{*}{ Hospitalization duration in days } & more than 5 & $200(62.2)$ & $137.86 \pm 27.17$ & \multirow{3}{*}{$* 0.94$} & \multirow{3}{*}{0.39} \\
\hline & between 6-10 & $89(24.1)$ & $142.31 \pm 32.23$ & & \\
\hline & less than 10 & $51(13.8)$ & $140.57 \pm 34.86$ & & \\
\hline \multirow{6}{*}{$\begin{array}{l}\text { The body region involved } \\
\text { (diagnosis) }\end{array}$} & head and neck & $42(11.4)$ & $142.40 \pm 33.23$ & \multirow{6}{*}{$* * 0.98$} & \multirow{6}{*}{0.43} \\
\hline & $\begin{array}{l}\text { rib cage and } \\
\text { stomach }\end{array}$ & $63(17.1)$ & $138.56 \pm 25.50$ & & \\
\hline & $\begin{array}{l}\text { pelvis, genitalia } \\
\text {,anus }\end{array}$ & $55(14.9)$ & $136.80 \pm 27.76$ & & \\
\hline & extremities & $65(17.7)$ & $136.77 \pm 27.14$ & & \\
\hline & Internal disease & $86(23.4)$ & $136.48 \pm 31.94$ & & \\
\hline & $\begin{array}{l}\text { several regions } \\
\text { together }\end{array}$ & $57(15.5)$ & $145.86 \pm 33.14$ & & \\
\hline \multirow[t]{3}{*}{ Ward } & emergency & $60(16)$ & $125.55 \pm 14.24$ & & \\
\hline & internal & $101(26.9)$ & $136.22 \pm 31.32$ & $* 10.41$ & 0.000 \\
\hline & surgery & $209(57.1)$ & $142.47 \pm 30.66$ & & \\
\hline Number of beds in rooms & $1-2$ & 81( 21.6) & $141.49 \pm 31.59$ & & \\
\hline & $3-4$ & $99(26.4)$ & 142.37 \pm 32.17 & $* 1.23$ & 0.18 \\
\hline & $>5$ & $195(52)$ & $136.30 \pm 27.09$ & & \\
\hline Hospitalization type & optional & $102(27.6)$ & $140.76 \pm 26.15$ & $* * 041$ & 046 \\
\hline & emergent & $268(72.4)$ & 138.41 $\pm \mathbf{3 0 . 8 1}$ & 0.41 & 0.40 \\
\hline Living place & city & $275(74.3)$ & $139.10 \pm 29.23$ & $* * 0$ & \\
\hline & village & $95(25.7)$ & $\mathbf{1 3 8 . 9 5} \pm \mathbf{3 0 . 7 5}$ & 0.44 & 0.96 \\
\hline Read the Bill of patients' Rights & Yes & $28(7.6)$ & $145.61 \pm 52.23$ & $* * 123$ & \\
\hline & No & 341(92.4) & $138.44 \pm 26.15$ & 1.23 & 0.22 \\
\hline
\end{tabular}

In psycho-mental domain, the highest mean of observations was reached when patients were called or addressed by their first and last name (3.71 \pm 1.33$)$, when they were teased or they were object of fun for their fear, pain, appearance and etc $(3.55 \pm 1.52)$, accompanying them during discharge from hospital $(3.40 \pm 1.24)$, or talking to them without respectful and polite tone $(3.39 \pm 1.21)$. The lowest mean of psycho-mental privacy observance was related to the time when personnel not introduced themselves to the patient $(2.45 \pm 1.14)$, not 
giving the patient to have a choice or participate in decision making $(2.71 \pm 1.21)$ and not trying to respect the patients' need of being alone (2.99 \pm 1.24$)$.

In informational domain, the highest means of privacy observance was reached when the patient personal information present in his medical records was not accessible for other patients $(3.97 \pm 1.14)$, when the patient being asked irrelevant personal information (3.34 \pm 1.39$)$, when she/he received instructions about his/her supportive sources, and insurance (3.16 \pm 1.25$)$. The lowest means observance in this domain were when the patient's conversation with physician was heard by other patients $(2.55 \pm 1.43)$, when the patient wasn't asked to give permission for participating or using his/her information in the research $(2.68 \pm 1.47)$ and when the patient was not instructed enough in diagnosis and treatment of his/her disease $(2.82 \pm 1.20)$.

Statistically, there was a significant difference in the patients viewpoints toward their privacy observance regarding gender, ward, and accent (Table 2).

The importance rate of privacy observance was reported in grades: very low $(7.7 \%)$, low $(13.5 \%)$, average (16\%), high $(28.7 \%)$, and very high $(34.1 \%)$.

Reported consequences of the privacy violated for patients were nervousness $(34.2 \%)$, annoyance $(32.6 \%)$, discouragement (7.1\%), disappointment (8.5\%), insecurity $(3.5 \%)$, sense of an uncontrolled situations $(2.7 \%)$, feeling of disability and futility $(2.4 \%)$, and sense of guilty $(3.6 \%)$.

The highest rate of privacy observance was done by physicians and nurses with $8.15 \pm 2.40$ and $7.62 \pm 2.53$ mean and SD respectively. The lowest observance belonged to the patients carriers and the security guards with $6.5 \pm 3.24$ and 5.92 \pm 3.14 , mean and SD respectively. The privacy violation was at a high level during ward cleaning and washing $(34.9 \%)$ or while the patient received visits from their families $(31 \%)$.

\section{Discussion}

Based on the viewpoints of most of the patient, privacy was in its entirety observed. Adib-Hajbagheri and Zehtabchi $(2014)^{20}$ and Yazdanparast et al. $(2016)^{21}$ studies showed that most of the participants reported that their privacy was observed at average and poor levels. Ardil and Korkmaz's study demonstrated that the patient' privacy observance was ignored and not respected. ${ }^{22}$ On the contrary in some studies including Kalary's et al. ${ }^{18}$ ) and Kuzu's research, ${ }^{23}$ the rate of privacy observance was reported higher than in the current report. These differences may be due to patient diversity in their cultural and social characteristics and expectations when the research was done.

In this study, the physical-corporeal privacy in most cases was observed. In Dadkhah's study, ${ }^{17} 42.5 \%$ and in Zirak et al. ${ }^{24} 49.2 \%$, of patients, pointed out that their corporeal- physical privacy was more often respected. However, in Harorani et al. ${ }^{25}$ study the level of physical privacy of patients was about $28 \%$. In this domain not knocking at the door before entering, or making the patient aware of entering in his/her physical privacy has not been observed, and the data are high as in this research. In Dadkhah's study, ${ }^{17} 43.9 \%$ of patients also stated that treatment staff had never asked any permission before entering their rooms.

Knocking at the door when entering the patient room is the sign of being aware of his/her physical intimacy (solitary). ${ }^{7}$ Edwards study indicated that some clients did not complain about the staff entering into their personal space, on the contrary, they thought that this act is a part of their duties or a part of treatment proceedings, but they pointed out that they accepted them to enter their space just due to existing disease ${ }^{26}$ The lowest observance happened when the patient was not acquainted with the circumstances and regulations of wards when admitted to the hospital. In Dadkhah and Aghajani's studies, a large when the not strictly necessary proportion of patients also stated that they were not acquainted with the ward medical and non-medical staff behavior so far from familiar circumstances ..$^{17,27}$

In the domain of physical-corporeal privacy, the highest mean of observance was related to avoiding touching the patient's body when not strictly necessary, avoiding sitting on the patient's bed, or observing gender covering, when not strictly necessary, parts of their bodies during physical examination or treatment. In Zirak et al. study also most of the participants stated that the staff always didn't sit on their bed. ${ }^{24}$ Getting permission before the examination was reported by only $45.5 \%$ of the participants, in Dehghani's study, but $64.7 \%$ did not touch if not necessary. ${ }^{28}$ On contrary, only $4 \%$ of participants in Zirak et al. study reported the covering of certain areas of the body when not strictly necessary, ${ }^{24}$ and in Adib-Hajbagheri and Zehtabchi study patients stated that exposing of patients' body in presence of the other people not strictly belonging to staff was mentioned by $70.3 \%$ of participants. ${ }^{20}$ In Aghajani and Dehghan Nayeri's study most of the cases reported providing care by male and female staff for male and female patients, respectively. ${ }^{27}$ But $42.2 \%$ of participants in Dehghani's study reported being cared for by same-sex staff as inappropriate. ${ }^{28}$ This difference may be due to different staff number and composition of each research environment and to different facilities, space, and culture in the settings of studies.

In the present research, the psycho-mental privacy of most of the patients was often respected. Aghajani and Dehghan Nayeri reported that psychosocial privacy was respected at the average and poor level in $31.9 \%$ and $28.9 \%$ of samples respectively. ${ }^{27}$ But In Dadkhah's study, $54.7 \%$ of patients expressed that their mentalpsychological privacy was often respected. ${ }^{17}$

This dimension is dealing with the human abilities which are necessary for them to form their norms and to whom and under what conditions they share or declare their thoughts, notions, and personal information with others. ${ }^{18}$ This dimension helps individuals to increasingly 
develop and improve their personal independence, selfassessment, personal identification, self-protection, and it can also expand or constrain human growth. ${ }^{7}$

Not taking permission from the patient for the presence of other people, different from staff, around the patient bed while diagnostic and therapeutic procedures or medical examination were performed, had the lowest level of observance in the psycho-mental privacy. One of the patient legal needs is to have the right to choose and making the decision voluntarily, as to allow learners or apprentices to attend or not to attend in his/her bed or not to take or not part to experimental research. ${ }^{29}$ So the observance of the domains of patient rights in the field of medical and non-medical education should also be taken into account as the field of research and treatment. Lack of observance of patient right to choose can bring annoyance for patients. ${ }^{30}$

Getting permission from the patient must be in a way that s/he would have opportunities to reject it without feeling any threats. ${ }^{31}$ In psycho-mental domain of privacy, the highest rate of observance was related to calling patients with their first or last names, avoiding making fun or teasing them or mocking patients for their fear, pain, appearance, and accent, Appropriate instructions must be given when patient is discharged from hospital, and instructions must be given to patients with respect and education. A large proportion of patients expressed their satisfaction for being called with the first and last name appreciating the possibility to talk politely with the staff in Dadkhah and Ghasemi studies. ${ }^{17,19}$ In Aghajani and Dehghan Nayeri study, most of the cases reported respect from the staff to their personal values and beliefs. ${ }^{27}$ In this research, the informational privacy of most patients' was observed. The information dimension was reported at a rather good level only in $30.6 \%$ in Aghajani's study. ${ }^{27}$ In Raee's study the patients' information privacy, was reported as very high as $86 \%{ }^{32}$ In Dehghani study, ${ }^{28}$ most patients reported informational privacy as optimal. The rate of patient rights observance and awareness was reported at an average level in Nasirian research. ${ }^{33}$ Information protection and prevention from giving incorrect information is one of the basic and important domains in hospitals and health centers. ${ }^{34}$ The examples for respecting patients information privacy are spending time to reply to patient questions, giving them understandable explanations about their concerns including disease type, and recovery percentage, long and short-term side effects of a disease, different therapies, and diagnostic methodologies, rehabilitation, and expenses. ${ }^{35}$ In this study the less observance rate of informational privacy can be due that this study was performed in an educational hospital in which a high number of medical and paramedical students are present at the patient bed asking to the patients alot of information and to the fact that mosto of the patients were hospitalized in rooms where other patients were present.
In this research, female patients reported their privacy observance much more than male patients. On the contrary, a study in Hamedan, female patients felt that their position or feeling of their importance hadn't been observed and they had been not respected. ${ }^{35}$ In AdibHajbagheri and Zehtabchistudy and also in Harorani et al. studies, there was no statistically significant relationship between gender and privacy observation. ${ }^{20,25}$ Maybe the more privacy observance was reported by women in the present study is due to delivery of care by Compliance (Entebaq) program based on Islamic rules which has led to providing a very high percentage of female care by female nurses. While this was almost impossible in men wards for lesser numbers of male nurses.

In this research, the patients of the surgical wards had a larger means of privacy observance than the patients of the medical wards. The patients of the surgical wards and those who had been hospitalized with their conscious and written consent. Conscious consent created some kinds of opportunities to ask questions and make a decision and provided in patients a great sense of satisfaction and control over situations ${ }^{38}$

The patients of the emergency department reported the lowest rate of privacy observance. Harorani et al. $(2017)^{25}$ also reported that in the emergency ward the patient privacy respect was reported to be very poor. The hospital emergency department was where the research was done, it is a crowded room that receives at the moment the largest number of patients from all over the province. The number of the emergency rooms is low, the beds in the room are herded and separated only by some curtains. In Dehghan Nayeri's and Aghagani study, privacy observance was weaker in rooms where beds were separated by curtains when compared with rooms where beds are separated by walls. ${ }^{16}$ Heydari's study also emphasized that a lack of physical space was an important and influential factor in privacy observance. ${ }^{14}$ Calleja mentioned that the design of the emergency department (i.e. low number of rooms, separation of the patient beds and separation of the beds only by curtains) was one of the most important causes of violation patient privacy. Especially when staff is revealing patient personal information being, and the information is heard by adjacent patients. ${ }^{39}$ It seems the structure and design of emergency departments need to be revised in order to protect patient privacy.

The privacy observance was significantly lower in the patients who spoke with a local accent than for patients speaking Persian. It is necessary to train and reinforce the health care providers to use interpersonal communication skills when dealing with patients not speaking Persian or speaking dialects.

There was no significant difference concerning the ages of the patient's viewpoints about their privacy observance in the hospital. The younger patients had assessed a higher level of their privacy observance in Dehghan Nayeri and Aghagani's research. ${ }^{16}$ Such a difference is 
the result of having high respect for people in Lorestan province for the elders. It may also be due to the less awareness of the elders towards the matter of privacy and its observance.

The score of the privacy observance was more for physicians than nurses in this research. In Kalroozi's et al .study, the rate of physicians' patient satisfaction was two times higher than nurses' privacy observance. Most of the reported nonsatisfaction with nurses is probably related to the lack of dedicating or devoting time when the required information must be done about the treatment and procedures necessary to be carried out. Patients seem to believe that if nurses take their right time to give information, they will feel more relaxed and the anxiety would decrease. Besides, cultural factors and privacy matters, patients always expect to follow physician prescriptions and these prescriptions must be taken into consideration. ${ }^{40}$ As evidence, cultural impunity of physicians in this study, the rate of non-observance of privacy while visiting and examining from physicians were taken into account more than nursing proceedings, actually, the score of the privacy observance for nurses was less than for physicians. However, nurses as persons who can easily enter the individual's privacy for delivering health is inevitable for them to violate sometimes patient privacy. Supporting patients' rights was possible for nurses only when they would have the necessary awareness of these matters. ${ }^{41}$ Also, one of the nursing problems is the shortage of human resources for nursing affairs all over the world, so it is not allowed to them to create an appropriate intrapersonal relationship with patients or to provide relevant training and instructions of patient needs. ${ }^{38}$

One of the merits of this research was to investigate all the domains of privacy and administering them on all hospital wards, probably expanding a generalization. It must be noticed that since the rate of privacy observance was investigated through patient viewpoints, one of the research limitations was to ignore if the patient responses were really honest, so only the moral points were emphasized in the entire taking care quality in order to assure and to make patients confident in their answers in a more precise and realistic manner.

In conclusion, patient privacy in its physical-corporeal and informational domains was observed, and, in particular, the psycho-mental domain was often respected. The privacy observance seemed to be more necessary for men than in the case of female. Training and reinforcement of staff sensitivity as respecting patient privacy consciously, as designing new hospital wards or departments, as revising also the family visiting regulations, as giving information to patients with proper and understandable language and finally making patients satisfied and ready to accept student training was the main object of the present study, patients were aware of their rights to protect their privacy in hospitals, and to adjust their expectations in an educational hospitals.

\section{List of acronyms}

ANOVA - ANalysis Of VAriance

\section{Authors contributions}

Both FV and SFG played a substantial role in the conception, drafting and revision of the manuscript.

\section{Acknowledgments}

Thanks ever so much to Mr. Bizhan Hozoori, Ms. Mahtab Eskini, and all patients who helped us participating in this research.

\section{Funding}

Authors thank Research and Technology of Lorestan Medical Sciences for generously undertaking the expenses of this project.

\section{Conflict of Interest}

The authors declare no financial, personal, or other conflicts of interest.

\section{Ethical Publication Statement}

We confirm that we have read the Journal's position on issues involved in ethical publication and affirm that this report is consistent with those guidelines.

\section{Corresponding Author}

Seyyedeh Fatemeh Ghasemi, Nursing and Midwifery Faculty, Lorestan University of Medical Sciences, Lorestan, Khorramabad, Iran Tel: +986616200140

Email: seyyedehfatemehghasemi@gmail.com

E-mails of co-author

Fatemeh Valizadeh: valizadeh.f@lums.ac.ir

\section{References}

1. Back E, Wikblad K. Privacy in hospital. J Adv Nurs 1998;27:940-5.

2. Margulis ST. Privacy as a social issue and behavioral concept. Journal of Social Issues 2003;59:243-61.

3. Low L, Lee D, Chan A. An exploratory study of Chinese older people's perceptions of privacy in residential care homes. J Adv Nurs 2007;57:605-13.

4. WHO. A declaration on the promotion of patients' rights in Europe. WHO Regional Office for Europe, Kluwer Law International, The Hague. 1994.

5. Parsapour A, Baghery A, Larijani B. Patient's rights charter in Iran. Acta Med Iran. 2014;52:24-8.

6. Leino-Kilpi H, Valimaki M, Arndt M, et al. Patient's autonomy, Privacy, and informed consent: Biomedical and health research. Amsterdam: Ios press 2000;40:105-15.

7. Yura H, Walsh M. The Nursing Process, AppletonCentury-Crofts, 4th edn, 1983.

8. Larkin G, Moskop J, Sanders A, Derse A. The emergency physician and patient confidentiality: a review. Ann Emerg Med 1994;24:1161-7. 
9. Harkreader H. Fundamental of nursing caring and clinical judgment. Philadelphia: WB Saunders; 2000.

10. Sawada N, Correia F, Mendes I, Coleta J. Personal and territorial space of the patients: A nursing ethics question. Med Law 1996;15:261-70.

11. Barlas D, Sama A, Lesser M. Is there a gender difference in patients' perceptions of privacy in the emergency department? Acad Emerg Med 1999;6: 546.

12. Jaefari S, Heidari S, Afshar Moghadam F, Mehrabi Y, Yeghmaii F. Survey of feelings to the observance of human territory and personal space in hospitalized patients in general surgical departments in Kermanshah. Journal of Nursing and Midwifery Faculty, Shahid Beheshti University of Medical Sciences 2003;13:26-33.

13. Schopp A, Leino-Kilpi H, Valimaki M, Dassen T, Gasull M, Lemonidou C, Scott PA, Arndt M, Kaljonen A. Perceptions of privacy in the care of elderly people in five European countries. Nurs Ethics 2003;10:39-47.

14. Heidari $M$, Anooshe $M$, Azadarmaki $T$, Mohammadi E. The Process of Patient's Privacy: A Grounded Theory. Journal of Shahid Sadoughi University of Medical Sciences 2011;19:644-54.

15. Meier E. Medical privacy and its value for patients. Semin Oncol Nurs 2002;18:105-8.

16. Dehghan Nayeri N, Aghajani M. Protecting patients' privacy by the medical team and its relation to patients' satisfaction. Hayat Journal of Faculty of Nursing and Midwifery, Tehran University of Medical Sciences 2010;16:13-22.

17. Dadkhah B, Ali Mohammadi M, Mozafari N. Respecting the rights and territory of patients in the hospitals of Ardebil city. Journal of Nursing and Midwifery Research 2004;9:37-44.

18. Kalagari Sh, Yazdi K, Mir Karimi Z, Behnampour N. Study of hospitalized patients' views about respecting to the human territory in the 5 Azar hospital in Gorgan Journal of Booie Nursing Faculty of Gorgan 2008;5:27-31.

19. Ghasemi M, Behnam Vashani H. Survey of respecting to patients territory and rights in Sebzevar hospitals. Journal of Sebzevar Faculty of Medical Sciences 1998;5:20-9.

20. Adib-Hajbagheri M, Zehtabchi S. Evaluation of elderly patients' privacy and their satisfaction level of privacy in selected hospitals in Esfahan. Medical Ethics Journal 2014;8:120-97.

21. Yazdanparast E, Davoudi M, GhorbaniSH, Abbaspoor M. The observance of different aspects of patient privacy: Analysis of elderly views. Medical Ethics Journal 2016;10:73-80.

22. Erdil F, Korkmaz F. Ethical problems observed by student nurses. Nurs Ethics 2009;16:589-98.
23. Kuzu A, Ergin A, Zencir M. Patients' awareness of their rights in a developing country. Public Health 2006;120:290-6.

24. Zirak M, Ghafourifard M, Aghajanloo A, Haririan H. Respect for patient privacy in the teaching hospitals of Zanjan. Iranian Journal of Medical Ethics 2015;8:79-89.

25. Harorani M, Pakniyat AG, Jadidi A, Sadeghi H, Varvanifarahani P, Golitaleb M, Basati M, Safarabadi M. The Extent of Maintaining the Privacy of Patients Hospitalized in Emergency Departments of Hospitals Affiliated with Arak University of Medical Sciences; a Cross-sectional Study. Iranian Journal of Emergency Medicine 2017;4:158-63.

26. Edwards S. An anthropological interpretation of nurses' and patients' perceptions of the use of space and touch. J Adv Nurs 1998;28:809-17.

27. Aghajani M, Dehghan Nayeri N. Survey of the various aspects of patient privacy in the selected emergency department of Tehran University of medical sciences. J Medical Ethics and History of Medicine 2008;2:59-69.

28. Dehghani F, Abbasinia M, Heidari A, et al. Patient's View about the Protection of Privacy by Healthcare Practitioners in ShahidBeheshti Hospital, Qom, Iran. Iran Journal of Nursing 2016;28:58-66

29. Williamson C, Wilkie P. Teaching medical students in general practice: respecting patients' rights. BMJ 1997;315(7116):1108-9.

30. Oflynn N, Spencer J, Jones R. Consent and confidentiality in teaching in general practice: the survey of patients' views on the presence of students. BMJ 1997;315(7116):1138-41.

31. Nesheim B. Commentary: respecting the patient's integrity is the key. BMJ 2003; 326(7380):100.

32. Raee Z, Abedi H. Nurses' Perspectives on Human Dignity of Hospitalized Patients. Iran Journal of Nursing 29;104:55-65.

33. Nasiriani K, Farnia F, Nasiriani F. Patients' rights observance in the viewpoints of the hospitals nursing staff in Yazd The scientific Journal of Legal Medicine 2007;13:33-7.

34. Mehrdad N, Parsayekta Z, Joolaei S. A study of patients' privacy overview. Hayat Journal of Faculty of Nursing and Midwifery, Tehran University of Medical Sciences 2004;10:87-95.

35. Rahimi Z, Farhanch A. Patient's dignity in observance in Hemadan's therapeutic centers. http://avid1388.blogfa.com/post-171.aspx (Accessed on 2012 Dec).

36. McKenna D, Triner W, Kardos K, McErlean M. Patients' Perception of Privacy During Various Phases of Emergency Care. Annals of Emergency Medicine 2005;46:S7.

37. Damschroder L, Pritts J, Neblo M, et al. Patients, privacy and trust: Patients' willingness to allow 
Human privacy respect

Eur J Transl Myol 30 (1): xx1-xx8, 2020

researchers to access their medical records. Social Science \& Medicine. 2007;64:223-35.

38. Lemonidou C, Merkouris A, Leino-Kilpi H, et al. A comparison of surgical patients' and nurses' perceptions of patients' autonomy, privacy and informed consent in nursing interventions. Clin Effect Nurs 2003;7:73-83.

39. Calleja P, Forrest L. Improving patient privacy and confidentiality in one regional emergency department - A quality project. Australasian Emergency Nursing Journal 2011;14:251-6.

40. Kalroozi F, Dadgari F, Zareiyan A. Patients' satisfaction from health care group in patient's bill of right observance. Iranian Journal of Military Medicine 2010;12:143-8.

41. Houshmand A, Joulaei S, Mehrdad N, Bahrani N. Nurses' information and their viewpoints about patient's rights and practical facilitators in clinics. Hayat 2007;12:57-66.

Submission: July, 29, 2019

Revision received: November 3, 2019

Acceptance: November 3, 2019 